\title{
Study of Behavioral Changes and Photosynthetic Activity of Euglenas gracilis in the Presence of Effluents from the Laboratory of Clinical Analysis
}

\author{
Luciano Henrique Pinto ${ }^{1}$, Suellen Zucco Bez², Julia Carolina Soares², Bruna Bonfim², \\ Qushmua Alzahrani ${ }^{3}$
}

${ }^{1}$ Assistant Professor at the Department of Pharmacy/Nursing/Medicine in UNIVILLE, Joinville, SC, Brazil

${ }^{2}$ Student at the Pharmacy Course in UNIVILLE, Joinville, SC, Brazil

${ }^{3}$ Voluntary Researcher in UNIVILLE, Joinville, SC, Brazil

Email: *lucianoefar@gmail.com

How to cite this paper: Pinto, L.H., Bez, S.Z., Soares, J.C., Bonfim, B. and Alzahrani, Q. (2020) Study of Behavioral Changes and Photosynthetic Activity of Euglenas gracilis in the Presence of Effluents from the Laboratory of Clinical Analysis. Journal of Environmental Protection, 11, 1015-1029. https://doi.org/10.4236/jep.2020.1112064

Received: September 21, 2020

Accepted: December 13, 2020

Published: December 16, 2020

Copyright $\odot 2020$ by author(s) and Scientific Research Publishing Inc. This work is licensed under the Creative Commons Attribution International License (CC BY 4.0).

http://creativecommons.org/licenses/by/4.0/

\begin{abstract}
Healthcare waste has now been increasingly studied in terms of the risks or dangers that can cause the environment and human health. Waste generated in clinical analysis laboratories (CALs) deserves attention, because, due to the advent of the concept of emergent pollution, it is doubtful if the materials or reagents are disposed in the sewage by CALs, which are currently considered non-contaminated or with low risk potential, under current legislation, may actually impact the environment with actions not yet understood. This study was experimental and conducted at the Environmental Laboratory of the University of the Region of Joinville. It was used Euglena gracilis (primary trophic level) algae exposed to effluents from five sectors of a CAL: Biochemistry, Hematology, Viral Load, Tuberculosis and Immunochemistry. Samples were collected from the siphons attached to the wash sinks of the CAL materials. To verify changes in algae that denote environmental danger, behavioral changes were analyzed via NGTOX, and chlorophyll concentration was calculated by chlorophyll extraction according to Mendel's method. Viral Load (VL) and Hematology (HT) sectors were the ones that most affected algae (Tukey test). In both sectors, there was inhibition of algae mobility and gravitaxy: in VL, due to the presence of chaotropic agents that denature organic structures; and in HT, due to the change in membrane permeability attributed to methylene blue. Also in HT, there was a search for algae adaptation by increasing the rise to the surface in order to overcome the lower luminosity due to the coloration of the environment, which also affects photosynthesis. Regarding the concentration of a-chlorophyll, the VL and HT were
\end{abstract}


the most affected as well, being the first one the one that had more concentration reduction because of the presence of chaotropic agents. Considering new parameters evaluated, the discarded compounds need to be better evaluated for risk, as they affect algal photosynthesis. Procedures for removal of these compounds should be considered.

\section{Keywords}

Ecotoxicity, Emerging Pollutants, Chaotropic Agent, Methylene Blue, Effluent from Clinical Analysis, Laboratory Residues

\section{Introduction}

Nowadays, healthcare waste has been increasingly studied in terms of the risks that can cause the environment and human health, mainly regarding the long-term exposure. Efforts have been performed in order to understand better this reality. It is known that effluents from healthcare facilities present potential risk and danger as they contain from endocrine disruptors to medicines and also microorganisms that somehow affect the health and the environment [1].

In turn, industries are the greatest responsibility for the generation of hazardous waste and, because of that, are the main target of inspection, even in comparison to laboratories. Although the increased monitoring and imposing fines, the Brazilian Association of Waste Treatment Companies [2] affirms that only $25 \%$ of the total of 33 million tons of industrial residues generated in the country are treated. The industrial residues are composed, in majority, by two factors Tavares [3] highlight: the accumulation and disposal of feedstock and supplies; and the inefficiency of conversion processes.

Regarding specifically to environment, these residues, that are commonly called emergent pollutants, may affect primary and secondary trophic levels, which modifies the ecosystem in a way that reaches the human being [4].

Recent studies have demonstrated that the concentrations found in the effluents of these emergent pollutants, even after suffering dilutions in water environments, may still cause damages. In an investigation performed by Machado et al. [5], it was pointed out that small quantities of some substances can cause long-term modifications in living beings, due to the bioaccumulation phenomenon. New researches to better comprehend phenomena like this are highly recommended in order to identify the risks and how to prevent them [6].

Considering the lack of information about long-term risks of emergent pollutants from healthcare facilities, the waste generated in clinical analysis laboratories (CALs) deserves attention, because these places discard various substances in the sewage, which may be a potential long-term source of environmental contamination. Therefore, CALs disposal guides to the leading question of this paper: may materials or samples considered non-contaminated or of low risk potential, under current legislation, and discarded in small quantities in sinks 
affect the environment?

It is important to say in Brazil there is a distance between the current legislation about the management of water resources, the reality of the wastewater and sewage treatment conducted by the wastewater treatment plant (WWTP) or sewage treatment plant (STP) and the current experience, which points out to emergent pollutants, i.e., dangers and risks to health and to the environment. Considering that, adaptations and rules that attend this new reality are required. Then, investigations like the present one are needed in order to obtain results that help to foment discussions that contribute to the adequacy of water treatments, with actualization of environmental legislation. In other parts of the world, organizations like European Union, the United States Environmental Protection Agency and the World Health Organization have already published guidelines and laws purposing on warning about the risks of the presence of hormones and other emergent products in water, as well demanding their removal, achieving to establish acceptable drinking water limits [1].

In this context, CALs need to be studied in order to comprehend better if there are emergent risks or not, especially due to the high participation in the generation of effluents. All the CAL sectors (here defined in Biochemistry Hematology, Viral Load, Tuberculosis and Immunochemistry) releases in average 20 liters of water a day, after washing the materials and executing in sinks other procedures. Depending on the quantity of performed tests, a CAL may dispose up to 120 liters of effluent every day in the public sewage [5].

Considering that Joinville city presents $33.4 \%$ of its treated domestic effluents and that the majority of laboratories is situated in areas that do not have public management of these effluents, all the produced waste is disposed in natura and has as final destination the Babitonga Bay [7]. Therefore, it is necessary to evaluate the potential of dangerous or environmental and ecotoxicological risk of the effluents generated by the CALs. The objectives of this paper were to verify if there is environmental toxicity risk of raw effluents from the CALs, adopting as the risk parameter the alterations that occur in Euglena gracilis (primary trophic level) algae, and to contribute to discussions on emergent pollution.

\section{Materials and Methods}

\subsection{Study Design}

This study was experimental and conducted at the Environmental Laboratory of the University of the Region of Joinville. It was used Euglena gracilis KLEBS algae, obtained from the collection of University of Göttingen, Germany. With regard to the algae, behavioral changes and modification on chlorophyll concentration will be evaluated, when in touch with samples from the analyzed CAL sectors.

The samples were gathered at the Joinville Municipal Clinical Analysis Laboratory, and the authorization was acquired via approval letter no. 051/2018/SMS/ GAB/GTES, from Joinville Municipal Secretary of Health. 


\subsection{Sample Collection}

To the analysis, two kinds of sample were collected from each sector:

[1] Water from access (WA): collected from the sinks of the laboratories, for which the same procedures were performed, in order to eliminate risks and biases.

[2] Raw effluents (RE): collected from siphons, with possible contaminants, to be ecotoxicologically analyzed.

The conduction of the study had the contribution of a CAL from Joinville city, in the Northeast of Santa Catarina, that permitted the sample collection in the five sectors of the laboratory (Table 1 ).

The WA samples were collected directly from the taps of the sinks used to wash the materials from each laboratory, with borosilicate glass jar previously sterilized, and they were used as control samples (water from the treatment plant).

The RE samples were collected from the siphons of the sinks used to wash the materials through a peristaltic pump. In this collection, borosilicate glass jars were utilized as well. For each sector, samples up to 2 liters were collected, and, after it, the samples were kept in polystyrene boxes with ice and away from the light until their packaging in freezers.

\subsection{Activity Calculation by Sectors}

One factor that must be considered here was the quantity of reagents disposed through the sinks and that compose the RE of the sectors. In order to have an idea of the dimension of the quantity produced by sector and its impact, the quantity of performed exams by sector in the period of one year was consulted, according to the laboratory records. These data are presented in results and discussion.

Table 1. Sectors of the laboratory studied.

\begin{tabular}{|c|c|}
\hline Sector & Description \\
\hline Hematology Sector & $\begin{array}{l}\text { Responsible for the processing of blood samples and exams } \\
\text { as hemograms, Rh factor, direct Coombs. }\end{array}$ \\
\hline Viral Load Sector & Responsible for exams like CD4, among others. \\
\hline Biochemistry Sector & $\begin{array}{c}\text { Responsible for exams like glucose, cholesterol, triglycerides, } \\
\text { AST, ALAT, creatinine, PCR, urea, calcium, } \\
\text { potassium, sodium, etc. }\end{array}$ \\
\hline Immunochemistry Sector & $\begin{array}{c}\text { Responsible for exams that use plasma separation tubes (serum): } \\
\text { HIV, Anti-HCV, Anti-Hbs, HbsAg, Anti-HbC, Siphilys, } \\
\text { Toxo IgG, Toxo IgM, etc. }\end{array}$ \\
\hline Tuberculosis Sector & $\begin{array}{l}\text { Responsible for sputum exams with collector pot, } \\
\text { as a sputum sample. }\end{array}$ \\
\hline
\end{tabular}

Source: primary. 


\subsection{Fraction Tests Preparation}

\subsubsection{Tests with Euglena gracilis Algae: Sample Preparation}

Considering one of the five analyzed sectors had two kinds of sample each, and the tests were performed in triplicate, 24 samples were collected and submitted to tests with algae and microcrustaceans, plus the control one (WA), compounding 32 samples to be investigated, as well as 32 algae culture for the tests.

Of each collected sample, a 5-mL aliquot was removed in order to be added to a 40 -mL culture of Euglena gracilis algae, and collections were conducted for the chlorophyll level and behavioral changes tests after 60 days of exposure, according to Nilsson et al.'s recommendation [8].

\subsubsection{Algae Behavioral Changes Evaluation by Biomonitoring via NGTOX}

The behavioral experiments with Euglena gracilis in effluents presence were performed using a tool of real-time biomonitoring called NGTOX, developed and homologated by Ecobabitonga Tecnologia Ltda. The instrument monitors, by a real-time image analysis, the algae behavior through different movement parameters of the photosynthetic unicellular flagellates [9].

The equipment contains a system of connections involving four silicone tubes responsible for the suction of cell culture of E. gracilis, water samples with hormones for the tests, water for sample dilution, and the disposal of the analyzed material.

Three pumps activated by peristaltic motors transported the cells, the diluent and the sample up to a glass bucket of $22 \mathrm{~mm}$ of internal diameter and $0.2 \mathrm{~mm}$ of thickness. The trial bodies in contact to the diluent were blended and transferred to an observation bucket, connected to a microscope, which captured the images of the cells in movement. The images were recorded by a charged coupled device camera and digitalized by a board connected to a microcomputer, in which they were presented in a monitor. The software calculated the movement parameters, the movement speed, the ascent rate, the average cell size, etc. After that, the samples were added, and the analyses were performed by the software one more time 10 minutes later. Any alteration on the movements, average speeds, ascent rates and cell size were calculated and compared with the previous results [3].

\subsection{3. $A$-Chlorophyll Examination Test on Algae: Chlorophyll Removal from the Algae and Spectrophotometer Analysis}

Aliquots were vacuum-filtered using Whatman ${ }^{\otimes} 47-\mathrm{mm}$ filter paper. The papers containing the filtered (precipitated cells) were transferred to a Falcon tube, received $5 \mathrm{~mL}$ of acetone and were after that kept at $4^{\circ} \mathrm{C}$ for 60 minutes, for the extraction of pigments. Then, the mixtures were centrifugated at $6000 \mathrm{~g}$ for 10 $\min$ at $4^{\circ} \mathrm{C}$ in order to aggregate on the waste cells.

The absorption spectrum of the supernatant was measured $665-705 \mathrm{~nm}$ for the chlorophyll reading and $400-445 \mathrm{~nm}$ for the carotenoids reading. For this, a spectrophotometer UV-160a Shimadzu was used. 
The chlorophyll concentration was calculated through the intensity of peaks found out on the spectrum, like the values plotted on an Excel ${ }^{\circ}$ sheet with the Lorenz formula for the concentration calculation.

\section{Results and Discussion}

\subsection{Production Estimate for an Influence Analysis of the Production Absolute Values}

In order to have an idea of the quantity that was produced and to verify how much the produced quantity could interfere or not in a possible environmental impact, the monthly average production was calculated for a certain period of the year.

According to the production records of the studied laboratory, it was seen that the total of performed exams during the period between January and December of 2018 (the survey period) were 1,005,557. Considering the quantity of exams conducted by the sectors, it was verified that the Biochemistry sector presented the highest number of exams in comparison to the other ones, followed by the Immunochemistry sector and the Hematology sector (Figure 1).

The high demand in the Biochemistry sector is justified by the nature of the performed exams. The majority of them are part of the medical clinic routine and required for chronical diseases tracking and controlling, like diabetes, liver and kidney diseases [10].

The next phase of the investigation was to know the reagents used by the sectors, regardless of demands, in order to understand if any of the components would be capable of affecting the algae activity.

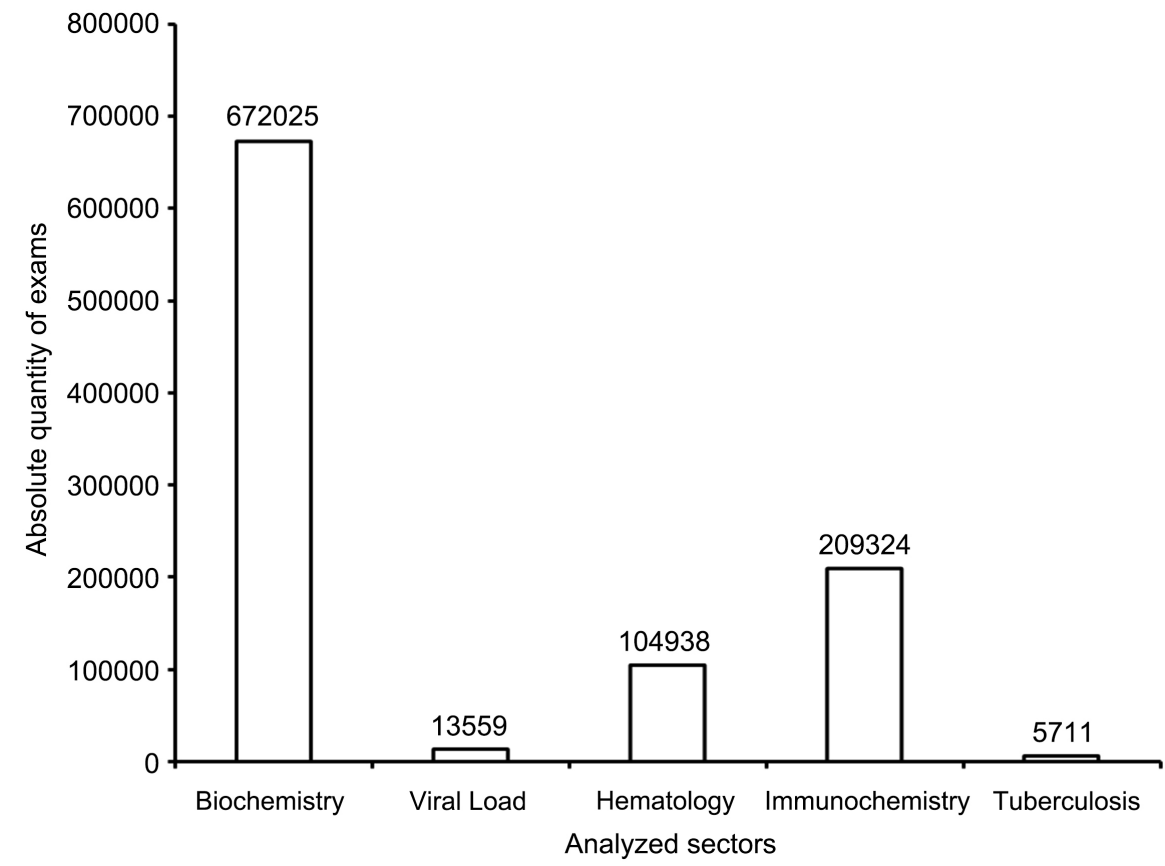

Figure 1. Total quantity of exams in the period between January and December of 2015, divided by sectors of the analyzed laboratory. Source: primary. 


\subsection{Effluent Composition by Sectors and Known Ecotoxicological Risk Aspects}

Many are the reagents used in laboratory exams. The majority of them are disposed in common sewer without the proper concerns, due to either neglection, or lack of rigid laws. These chemical compounds vary from dyes used for contrasts in cells for chaotropic agents to protein dehydration, as well as methanol traits and iron microparticles [10].

The dyes used in the sectors are listed in Table 2, and the dyes' chemical composition is detailed in Table 3.

In the Hematology sector, the dyes are used in a blood smear technique. They are also called panchromic and correspond to a mixture of dyes with varied characteristics, that in appropriate conditions dye the nuclear and cytoplasmatic components of leukocytes in shades of red and blue [11].

Table 2. Dyes used in the analyzed sectors.

\begin{tabular}{|c|c|c|}
\hline Sector & Dye & General Composition \\
\hline Hematology sector & $\begin{array}{c}\text { GIENSA }^{\oplus} \\
\text { MAY GRUNWALD }\end{array}$ & $\begin{array}{l}\text { - Giemsa dye } \\
\text { - Glycerol } \\
\text { - Methanol }\end{array}$ \\
\hline Tuberculosis sector & ZIEHL-NEELSEN ${ }^{\circledR}$ & $\begin{array}{l}\text { - Basic fuchsin } \\
\text { - Ethyl alcohol } \\
\text { - Methylene blue } \\
\text { - Hydrochloric acid } \\
\text { - Carbolized crystal violet } \\
\text { - Lugol's solution } \\
\text { - Alcohol-acetone bleaching solution } \\
\text { - Carbolized gram's fuchsin }\end{array}$ \\
\hline
\end{tabular}

Source: kit instructions.

Table 3. Dyes' chemical composition.

\begin{tabular}{|c|c|}
\hline Dyes & Chemical Composition \\
\hline Giemsa & $\begin{array}{c}\text { Methylene blue } \\
\text { Azure B } \\
\text { Azure A } \\
\text { Azure C } \\
\text { Thionine }\end{array}$ \\
\hline Basic fuchsin & $\begin{array}{c}\text { Rosalinine chloride } \\
\text { Pararosaniline chloride }\end{array}$ \\
\hline Carbolized fuchsin & $\begin{array}{c}\text { Rosalinine chloride } \\
\text { Pararosaniline chloride } \\
\text { Ethyl alcohol } \\
\text { Cast phenol }\end{array}$ \\
\hline Carbolized crystal violet & Pararosaniline chloride \\
\hline Lugol & Potassium iodide \\
\hline
\end{tabular}

Source: kit instructions. 
In the Tuberculosis sector, there is the Ziehl-Neelsen reagent, which consists on highly lipophilic composes that promote the dyeing of the cell wall bacteria with highly lipophilic characteristics. Bacteria that have this kind of membrane are resistant to common coloring methods. Ziehl fuchsin dyes all the bacteria in red, and, after the bleaching with alcohol-acid, only the acid-fast bacilli will keep the color. In order to make the visualization easier, the bottom is dyed with methylene blue, establishing a clear contrast between cell elements and other bacteria (blue ones) and the acid-fast bacilli (red ones) [11].

In the Hematology and Tuberculosis sectors, the common dye is the methylene blue, represented in Figure 2. It is a mixture of compounds that are able to present potential contaminant due to their chemical characteristics, like high stability and lipophilicity level, and to make them easily be in contact with cell membranes [12].

In the Viral Load sector, the reagents used are listed in Table 4, in which there are three kinds of buffer solutions utilized for protein dehydration in molecular biology exams.

The binding buffer solution promotes the quantification of a certain DNA and is composed by a chaotropic agent, the guanidinium isothiocyanate (Figure 3 ).<smiles>CN(C)c1ccc2nc3ccc(N(C)C)cc3[s+]c2c1</smiles>

Figure 2. Methylene blue chemical structure, composed of two aromatic rings and a central heterocyclic one, used as a dye in laboratorial exams. Source: Lima et al., 2017.

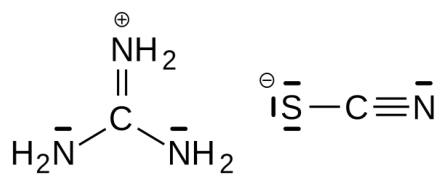

Figure 3. Guanidinium isothiocyanate's structure, a nitrogen compound with three highly reactive nitrogen, used for dehydrating proteins and for molecular biology exams. Source: Esmali et al., 2018.

Table 4. Buffer solutions chemical composition used in the viral load determination.

\begin{tabular}{ccc}
\hline Sector & Reagent & Chemical Composition \\
\hline \multirow{2}{*}{ Binding buffer } & Guanidinium isothiocyanate \\
& Ethanol \\
& Wash buffer & $\mathrm{NaCl}$ \\
& Elution buffer & EDTA \\
& Silica \\
\hline
\end{tabular}

Source: analyzed kit instructions. 
It decreases the hydrogen bonds in the middle, which makes the viral DNA links to the silica, and this process is easier due to the ethanol presence. The chaotropic agents are capable of interfere in the organic structures, causing the protein and macrocells dehydration. This way, it's seen the reduction of enzymatic activity and the cell stress induction, which can be a risk for the living beings, depending on the exposed quantity [13].

Taking into account this used reagents survey, which are disposed directly in common sewer, the next idea was to study the behavioral changes and the chlorophyll alterations in algae to verify if these modifications are related to the reagents cited here and if they have any risk or environmental hazard.

\subsection{Behavioral Analysis of Euglena gracilis Algae in the Presence of Effluents from the Sectors}

The behavioral changes of algae before the effluents are demonstrated in Figure 4 , and they were obtained via NGTOX. It was seen the WA from the treatment network did not affect the behavior of Euglena gracilis algae in a significant way, in comparison to the control. However, under the exposure to the effluents from the analyzed sectors, situations of stimulus and inhibition in the studied behavior were observed. The algae exposed to the Viral Load, Tuberculosis and Hematology sectors presented reduced mobility, and r-value inhibitions were noticed both in Viral Load and Hematology sectors. The mobility is related to the proper flagellar functioning of algae, and the r-value to the feeling of collectivity. The two conditions prevent the better photosynthetic exploitation due to the difficulty of going to the surface and obtaining the ideal luminosity to the activity [8].

Moreover, Hematology sector went through speed inhibition, unlike the Viral Load sector, in which this parameter worked as a defense mechanism of algae before the imposed adversity. In Hematology sector, the stimulus observed and correspondent to the defense mechanism occurred due to the increment of going to the surface. The same was seen in the Tuberculosis sector. This behavior aims to try to solve adverse conditions regardless to the low photosynthetic efficiency and to seek greater luminosity in the surface [8].

Mobility and r-value changes may have a multiple of origins, from the mere viscosity alteration promoted by any modification in the environment density to variations in the algae's physiology. Viscosity was not a reason for the alterations observed here, because changes in the viscometer were not seen. Physiology alterations are a condition that deserves attention, since they compromise algae's vital activities, which may involve manifestations of any environmental impact. Mobility altered by physiological changes derived from the environment contaminants interferes in the going to the surface seeking for luminosity. The same occurred with $r$-value, that measures the algae dispersion and the feeling of collectivity reduction. Under this dispersion, not all the algae reach the surface in order to obtain luminosity, what jeopardizes the photosynthesis. In order to survive, algae adopt defense compensatory and adaptative mechanisms [14]. 


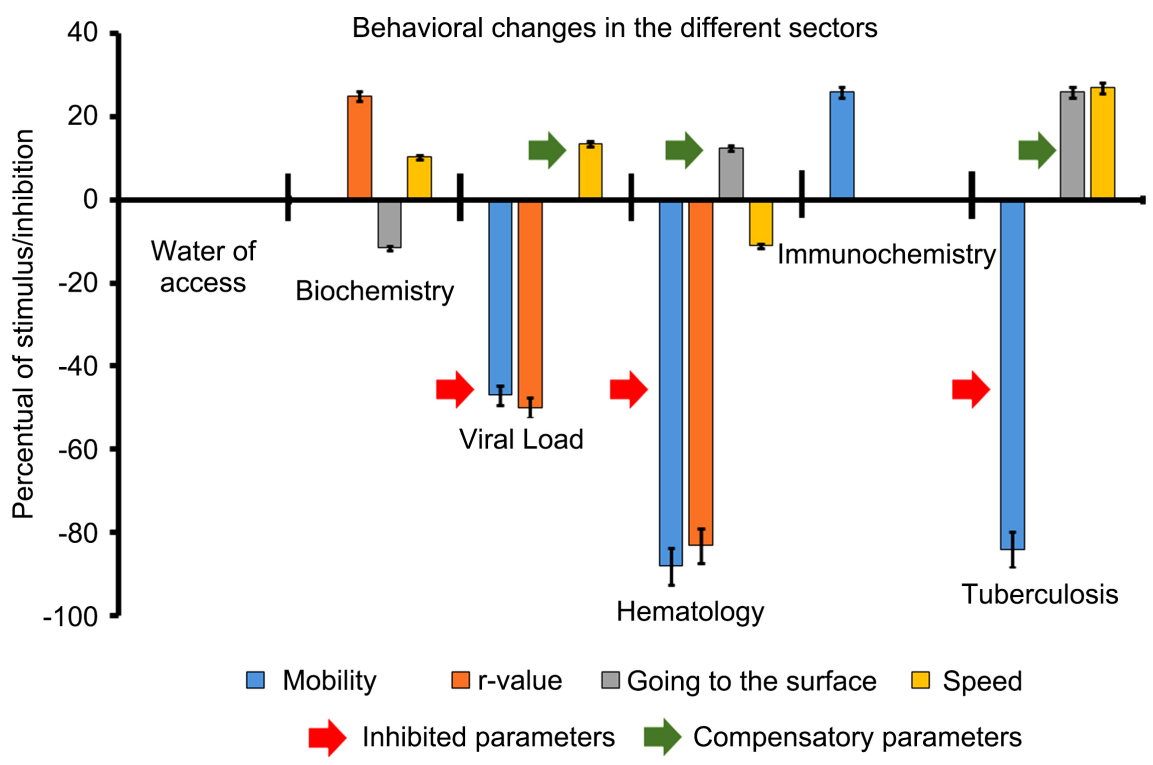

Figure 4. Behavioral changes analysis via NGTOX. It was seen the water of access from the treatment network did not affect the behavior of Euglena gracilis algae. However, under the exposure to the effluents, there were both stimulus and inhibition situations. The Viral Load and Hematology sectors had inhibition in mobility and in r-value as well. Moreover, Hematology sector went through speed inhibition, being this parameter a compensatory condition in Viral Load sector. The compensation in Hematology occurred through the increment of going to the surface, in order to try to solve the adverse condition.

To better comprehend the relation between the effluent compounds and the manifestations observed in the algae behavior, it was taken into account what each reagent could cause to $E$. gracilis.

In Hematology sector, both mobility inhibition and $r$-value reduction occurred due to the presence of the dyeing methylene blue, which, in accordance with Yamashita et al. [15], modifies the permeability of the plasmatic membrane in a mechanism of photodynamic action, causing the formation of reactive-oxygen species (ROS), which changes the membranes lipoprotein formation (Figure 5). In addition, the dyeing also made more difficult the luminosity in areas further the surface, jeopardizing the photosynthesis, what forces the algae to put extra effort in going to the surface as a defense mechanism [3]. This phenomenon was also observed in Hematology sector.

On the other hand, in Tuberculosis sector, the affected parameter was the mobility, likewise in Hematology sector, but $r$-value was not changed. Two compensatory mechanisms were also noticed: going to the surface, here understood as an effort to overcome the low luminosity, as well as it occurred in $\mathrm{He}-$ matology sector, since in this sector the dyeing is also disposed; and speed increase. The inhibition of only one parameter and the ability of adopting two defense mechanisms are possibly due to the absence of other potentially toxic compounds that are found in Hematology sector disposal, like the methanol, for example. Another hypothesis is the low disposed quantity, since the analyzed laboratory runs a few exams. 


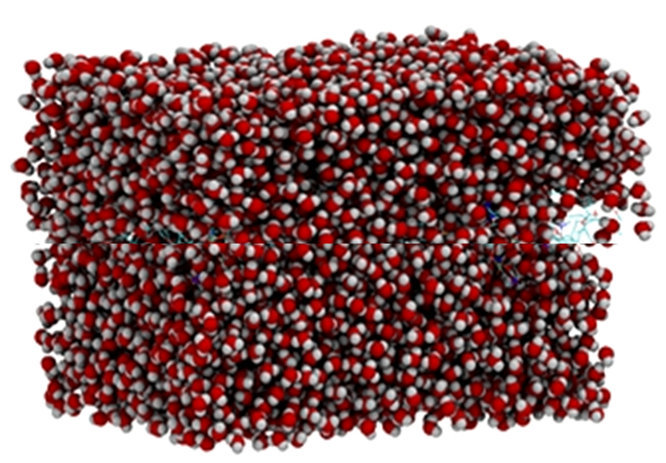

Entire membrane

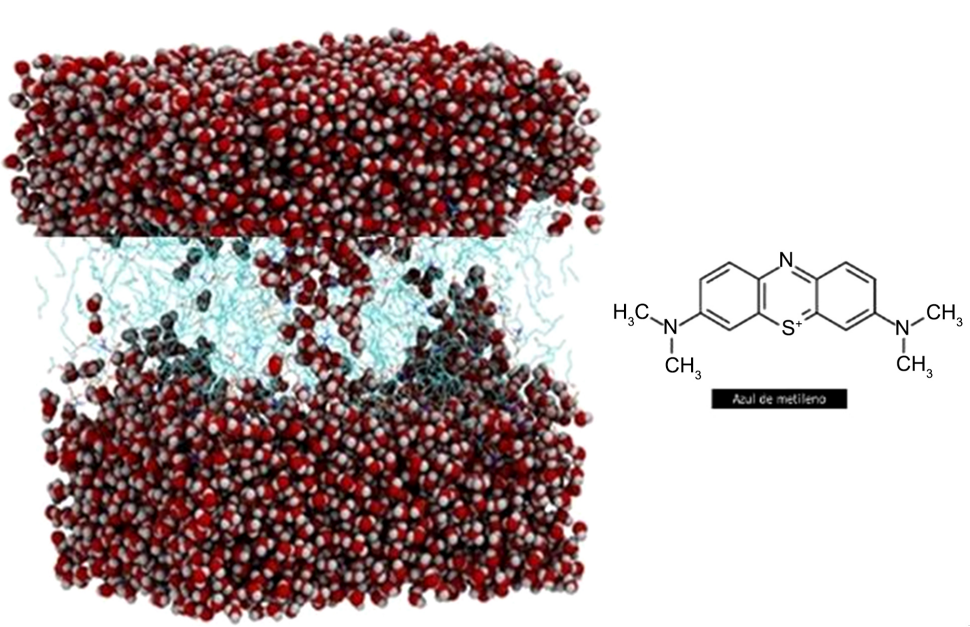

Membrane modified due to the presence of methylene blue

Figure 5. Membrane permeability alteration under the presence of methylene blue. Studies conducted by Yamashita et al. (2019) found out microorganism function compromise due to the permeability change. Source: authors.

In Viral Load sector, in turn, the inhibition both in mobility and in r-value was provoked by the chaotropic agents, which, among the already mentioned activities, cause macromolecules denaturation, that affects the flagellar movement, as well the gravitaxy, important conditions to a proper mobility and r-value perception. In this sector, the defense mechanism was stimulated due to the speed increase, since it was the best way to reach luminosity under the limitations imposed by the guanidinium isothiocyanate [16].

Considering these observations, it was necessary to verify more in-depth the photosynthesis, here evaluated according to the possible alterations in chlorophyll concentrations.

\subsection{A-Chlorophyll Concentration Analysis under the Effluent Exposure and Alterations Check}

Changes in chlorophyll concentration are conditions that denote environmental risk, since the algae's vital activities will be modified and impacts in primary trophic level will occur. The analyzed chlorophyll was the a one, because it is more common in photosynthesis [17]. In conditions under effluent exposure, it was seen reduction in a-chlorophyll concentration in comparison to the control, according to Figure 6. Hematology sector presented the highest decline in concentration when compared to the other sectors.

When the a-chlorophyll concentration calculation according to Lorenz's equation was performed, it was observed significant reduction in comparison to the control in Viral Load and Hematology sectors, and the latter presented the lowest concentration, as shown in Figure 7.

The diminished concentration in Hematology sector is justified by the photodynamic action caused by the methylene blue, already mentioned. This dyeing, when in presence of certain wavelengths, may lead to the production of ROS, species that respond to all cellular components, including chlorophyll [18]. 


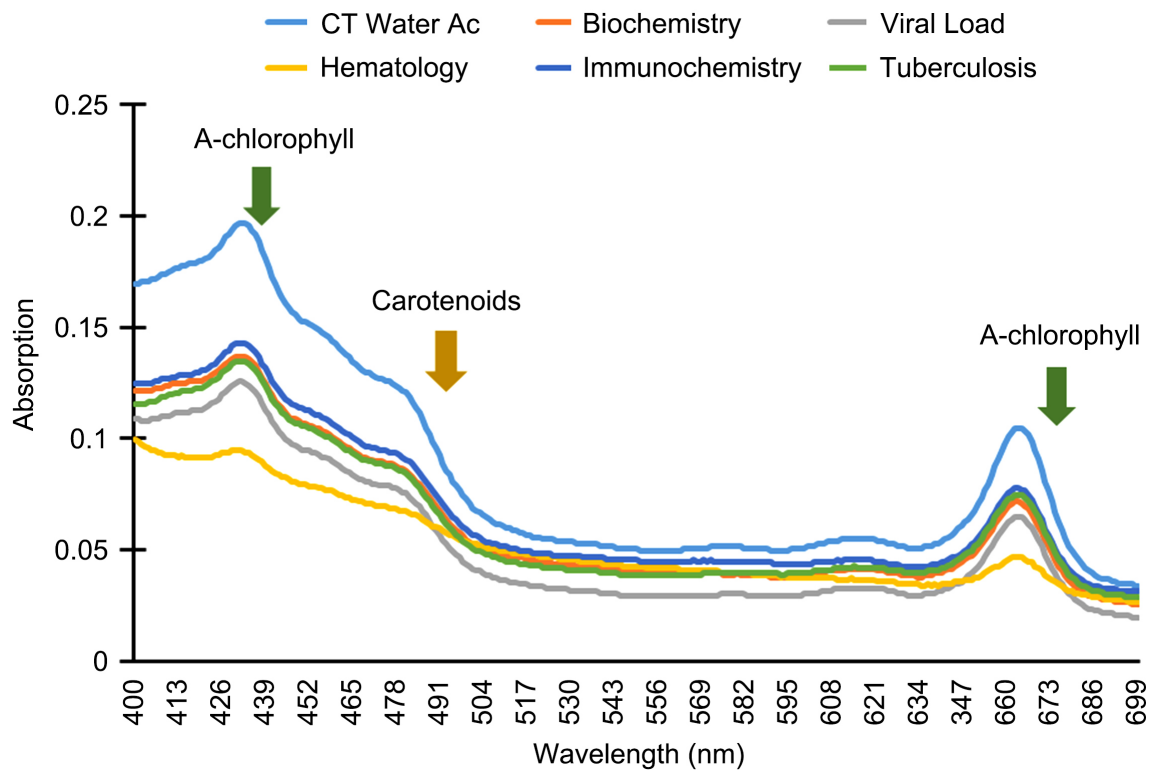

Figure 6. Absorption spectrum in UV light of the culture of algae exposed to effluents. It was seen the presence of peaks corresponding to a-chlorophyll (green arrow), as well as to carotenoids (yellow arrow). The algae that only had contact with the water from the treatment network reached higher peaks and the furthest distance from the $430-\mathrm{nm}$ carotenoid peak. Hematology sector presented the lowest peaks and the highest proximity to carotenoid peaks. Source: authors.

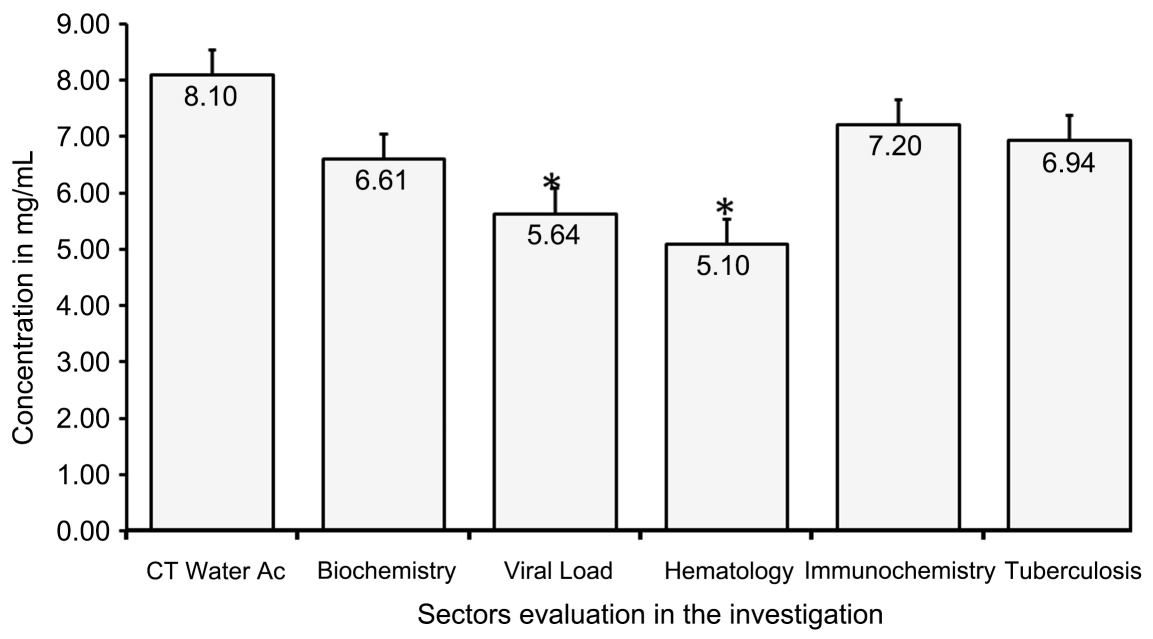

Figure 7. $A$-chlorophyll concentration according to Lorenz's equation. Viral Load and Hematology sectors presented significant reduction in chlorophyll concentration. The other sectors showed values similar to the control ones, conducted with the water from the treatment network. Source: authors.

Then, besides the deleterious effect on the membrane permeability, there is the photodynamic activity, also adverse to algae's vital activities, which clears out the higher behavioral inhibitions observed in the test using NGTOX.

In Viral Load sector, the reduction in concentration occurs due to the guanidinium isothiocyanate. This compound has nitrogens that ionically link on the magnesium present in the environment [19], as shown in Figure 8 and Figure 9. 


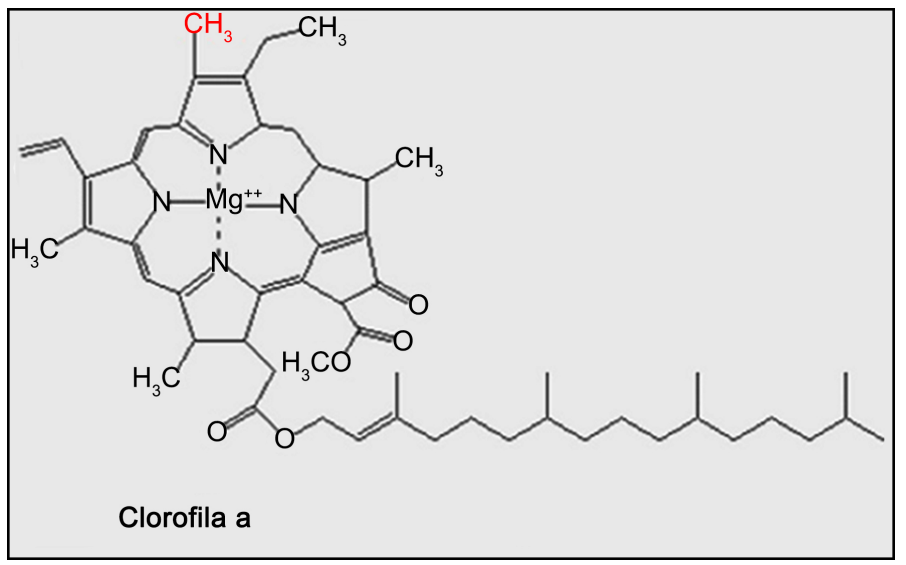

Figure 8. $A$-chlorophyll in its original composition, with the presence of magnesium in the molecule. Source: authors.

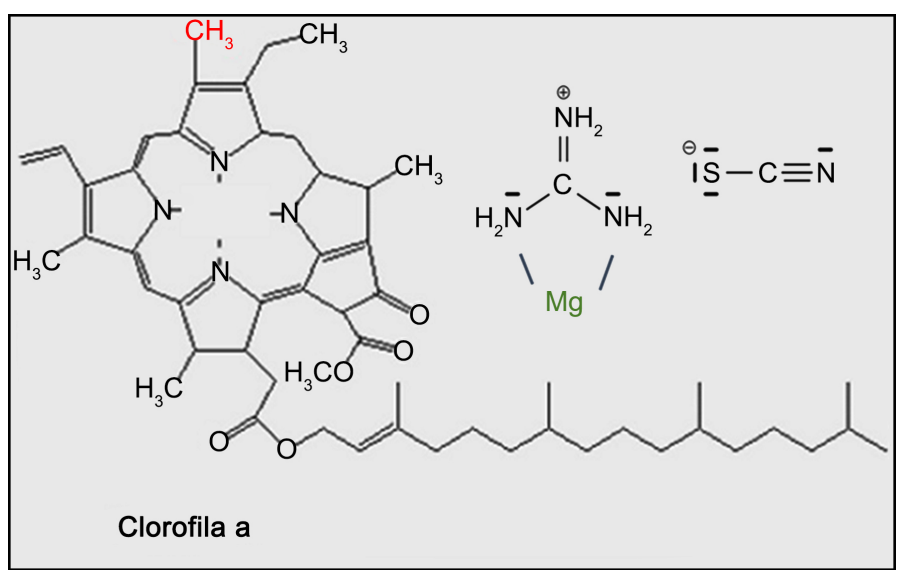

Figure 9. Presence of guanidinium isothiocyanate as sequestrant of magnesium. Source: authors.

This way, there is the sequester of the ions present in the chlorophyll molecule, dehydrating it. This is the reason of the concentration reduction observed in the experiments.

\section{Conclusions}

Since knowing the alterations effluents from the analyzed sectors might cause to the primary trophic level, here represented by E. gracilis algae, and understanding the environmental risks involved, the hypothesis that the environment may have been suffering dangerous alterations or environmental risks caused by the presence of effluents, being these alterations different among the laboratories, is true, according to the experiments performed by this investigation.

The Brazilian normative RDC ANVISA no. 306 [20], which deals with solid waste disposal, involves a lot of questions. However, concerning dyeing disposal, it is permissive. This study has evidenced that dyeing waste and chaotropic agents, disposed directly in the sink/sewer, fit under environmental risk, since they promote changes in algae, letting them more inclined to a hazardous situa- 
tion. Consequently, there are also indirect damages to environment and human health, taking into account the unbalance this trophic level may manifest in long term.

A revision of the current legislation is always required, because, due to the advent of emergent pollutants, what was previously understood as a risk nowadays counts on the presence of new compounds that need to have its disposal regulated.

Therefore, biomonitoring data found out were relevant in order to obtain more knowledge and to be aware of the importance of the issue, indicating the possibility of environmental toxicity provoked by the effluents from the CALs. long-term revisions of conducts and legislations trying to minimize the problems related to this kind of emergent pollutants need to be thought.

\section{Funding Statement}

Investigation performed with funding by the Research Support Funds of the University of the Region of Joinville (Univille).

\section{Acknowledgements}

The researchers thank Univille and the Research Support Funds that make possible the development of the Environmental Impacts and Health Integrated Program (ECOSAM).

\section{Conflicts of Interest}

The authors declare no conflicts of interest regarding the publication of this paper.

\section{References}

[1] Windfeld, E.S. and Brooks, M.S.-L. (2015) Medical Waste Management-A Review. Journal of Environmental Management, 163, 98-108.

https://doi.org/10.1016/j.jenvman.2015.08.013

[2] Abetre, Brazilian Association of Waste Treatment Companies (2016) Study on the Economic and Financial Aspects of Landfill Implementation and Operation. Fundação Getúlio Vargas, Rio de Janeiro.

[3] Pinto, L.H., et al. (2016) Environmental Toxicity of Effluents from Different Laboratories in a Master Pharmacy. Environment and Water-An Interdisciplinary. Journal of Applied Science, 11, 819.

[4] Oliveira, T.S. (2018) Environmental Contamination From Health-Care Facilities. In: Boxall, A.B.A. and Kookana, R.S., Eds., Health Care and Environmental Contamination, Elsevier, Amsterdam, 7-19. https://doi.org/10.1016/B978-0-444-63857-1.00002-4

[5] Machado, C.K., Pinto, L.H., Del Ciampo, L.F., Lorenzi, L., Hack Gumz Correia, C., Häder, D.P., et al. (2014) Potential Environmental Toxicity from Hemodialysis Effluent. Ecotoxicology and Environmental Safety, 102, 42-47. https://doi.org/10.1016/j.ecoenv.2014.01.009

[6] Kist, L.T., et al. (2016) Management and Quantification of Waste from Health 
Services: Case Study. Techno-Logic, 20, 111.

[7] Gueretz, J.S., Da Silva, F.A., Simionatto, E.L., Férard, J.-F., Radetski, C.M. and Somensi, C.A. (2020) A Multi-Parametric Study of the Interaction between the Parati River and Babitonga Bay in Terms of Water Quality. Journal of Environmental Science and Health, Part B, 55, 257-264. https://doi.org/10.1080/03601234.2019.1685813

[8] Nilsson, L. and Ekelund, N.G.A. (2008) Effects of Estrogenic Substances on the Movement of Euglena Gracilis. SIL Proceedings, 1922-2010, 30, 357-359. https://doi.org/10.1080/03680770.2008.11902142

[9] Erzinger, G.S., del Ciampo, L.F. and Häder, D.P. (2011) Equipment and Process for Toxicity Analysis in Aquatic Systems. No. 0000221105523696, Brazil National Institute of Industrial Property, Brasilia.

[10] Barth, J.H. (2011) Clinical Quality Indicators in Laboratory Medicine: A Survey of Current Practice in the UK. Annals of Clinical Biochemistry, 48, 238-240. https://doi.org/10.1258/acb.2010.010234

[11] Freitas, M., Machado, A., Doria, A., Hage, R. and Khouri, S. (2018) Evaluation of the Association of Photodynamic Therapy with Methylene Blue to Safeteam ${ }^{\varpi}$ Oil on Candida Albicans Isolated Catheter Straps. Univap Magazine, 24, 100-110. http://dx.doi.org/10.18066/revistaunivap.v24i44.380

[12] Lima, R.C.A., Zapelão, K., Parladore, D.F.S. and Anschau, A. (2017) Potential for Removing Methylene Blue Using Malt Bagass in Natura through Factorial Planning $2^{2}$. Blucher Chemical Engineering Proceedings, 1, 2682-2687.

[13] Esmaili, I., Mir Mohammad Sadeghi, H. and Akbari, V. (2018) Effect of Buffer Additives on Solubilization and Refolding of Reteplase Inclusion Bodies. Research in Pharmaceutical Sciences, 13, 413-421. https://doi.org/10.4103/1735-5362.236834

[14] Häder, D.-P. and Lebert, M. (1985) Real Time Computer-Controlled Tracking of Motile Microorganisms. Photochemistry and Photobiology, 42, 509-514. https://doi.org/10.1111/j.1751-1097.1985.tb01602.x

[15] Yamashita, K., Yamada, K., Suzuki, K. and Tokunaga, E. (2019) Noninvasive and Safe Cell Viability Assay for Euglena Gracilis Using Natural Food Pigment. PeerJ, 7, e6636. https://doi.org/10.7717/peerj.6636

[16] Pinto, L.H., Sierth, R., Schulter, L.S., Fausto, M.C., Del Ciampo, L., Soares, J.C. and Erzinger, G.S. (2017) Changes in the Behavior of Euglenas Gracilis Algae in the Presence of $17 \alpha$ Ethinylestradiol and $17 \beta$ Estradiol. Brazilian Journal of Aquatic Science and Technology, 20, 30. https://doi.org/10.14210/bjast.v20n2.7471

[17] Aemiro, A., Watanabe, S., Suzuki, K., Hanada, M., Umetsu, K. and Nishida, T. (2019) Effect of Substituting Soybean Meal with Euglena (Euglena gracilis) on Methane Emission and Nitrogen Efficiency in Sheep. Animal Science Journal, 90, 71-80. https://doi.org/10.1111/asj.13121

[18] Wan, W.-L., Tian, B., Lin, Y.-J., Korupalli, C., Lu, M.-Y., Cui, Q.H., et al. (2020) Photosynthesis-Inspired $\mathrm{H}_{2}$ Generation Using a Chlorophyll-Loaded Liposomal Nanoplatform to Detect and Scavenge Excess ROS. Nature Communications, 11, Arrticle No. 534. https://doi.org/10.1038/s41467-020-14413-x

[19] Tsarpali, V. and Dailianis, S. (2018) [omim][BF4]-Mediated Toxicity in Mussel Hemocytes Includes Its Interaction with Cellular Membrane Proteins. Aquatic Toxicology, 203, 88-94. https://doi.org/10.1016/j.aquatox.2018.08.004

[20] National Health Surveillance Agency (2006) Health Care Waste Management. Editora Anvisa, Brasília. 